ISBN 978-81-936279-8-3

13th International Conference on Language, Literature, Social Sciences and Interdisciplinary Studies

(LLSSI-18)

London (UK) June 25-26, 2018

\title{
Intermingling of Present Technology and Teaching of English
}

\author{
Dr. Shikha Agarwal
}

Assistant Professor, Swami Keshvanad Institute of Technology and Gramothan, Rajasthan, India

\begin{abstract}
Now-a-days we have sophisticated technology and the aim of my paper is to outline the ways in which we should use technology and how it helps in teaching of English.Today everybody is technology savvy and spends most of the time using gadgets. In this paper I have tried to find out different modern technologies useful for English classrooms and also to discuss their pros and cons. The last two decades have witnessed fast spreading of English language. Even the countries like are Japan and China which were orthodox in using their mother tongue are now promoting teaching and learning of English. English is the first international language widely spread to whole cosmos. A revolution due to the onset of technology has changed the dynamics of various industries, and has also influenced the industries and the way people interact and work in the society. This rapid rising and development of information technology has offered a better pattern to explore the new teaching model. As a result, technology plays a very important role in English teaching. Using multimedia to create a context to teach English has its unique advantages. This paper tries to analyze the necessity of technology to language teaching and also brings out the problems faced by using these technologies. It also aims to make English teachers aware of the strategies to use them in an effective manner.
\end{abstract}

Keywords: Technology,multimedia,

Keywords: Present, technology, Teaching.

\section{Why do we need Technology?}

- We are living in an era where technology is transforming the world of global communication. New genres of communication are being created and we need to support and enable our students to use these new forms of communication in English, just as we are trying to broaden the scope for self expression and creativity, democratizing the role of the media and making it possible for more people to have a voice and play a role in defining the society that we live in. English Technology can enable us to extend the reach of our classroom and take our students into a world of authentic language use where they can really use their English language skills to communicate, collaborate and participate in activities that are relevant to their own lives and interests.

- Darwin's theory of Survival of the fittest is relevant even now. Either adjust or perish ; so technology helps us to accommodate with our surroundings and it also has a supporting role to play within our own professional practice, and sound use and understanding of how technology can be used and can help us to work more effectively and efficiently as teachers and cope with an ever-increasing workload.

Here I would talk about two technical tools:

Adapt your course book and video-sharing which can make a difference in the classroom. 


\section{Why adapt a course book?}

- Many of our students are growing up with technology as a natural part of their everyday lives. They will most certainly need to have an understanding of how to use it if they intend to have any kind of profession, so developing our students' ability to use technology in a meaningful way is very important.

- Writing and publishing a course book takes a long time. Once the coursebook is published, it needs to have a lifespan of a number of years, which means that the coursebooks teachers are using in the classroom today may well have been written ten or more years ago. By contrast, technology changes so quickly that any attempt to deal with it through the traditional coursebook medium can be rendered obsolete even before the book is published. So, to deal with this problem, it is the responsibility of the teachers to bridge this gap and adapt, supplement and replace elements of our coursebooks in order to meet the increasing digital literacy needs of our students.

- Using technology to adapt some aspects of the coursebook can also enhance our students' abilities to engage with the materials and broaden their potential to extend beyond the classroom. Particularly, it offers us great opportunities to develop more motivating and engaging homework tasks for our students.

- Technology can enable students to work in new ways and collaborate more easily. Developing their ability to work collaboratively online can significantly help them to become more autonomous, enhance their ability to learn from each other and develop an important 21 st century digital literacy.

- Look for web-based tools that can help students to develop their knowledge of the vocabulary.

- Record audio versions of reading texts so that students can also hear the text.

- Supplement themes from the coursebook by searching for appropriate texts online.

- Develop digital reading skills by getting students to find information from a combination of online texts and videos.

- Help students to understand how to search for materials which can help them to supplement themes from their coursebook.

- Create interactive digital activities to help students revise texts, vocabulary or grammar points.

- Help our students to develop digital study skills by getting them to use computers or other digital devices to make notes.

\section{Tips for adapting course book}

- Remember that your coursebook is protected by copyright, so if you intend to copy images or text from it and save those as digital copies, then you will need to ask for permission from the publisher.

- It's best to create digital materials your students can access from home; that way, you don't have to face the potential problems related to connectivity in the classroom and your students will be able to get 'hands-on' experience on their own computer.

If working with technology is new to your students, don't expect things to run smoothly the first time you try them. Expect a few problems and work towards developing students' skills so that by the second or third time you try something, they spend less time understanding the technology and more time engaging with the task of learning language.Look for ways in which the technology can be applied to really enhance and extend the work of the coursebook, rather than simply act as an entertaining gimmick. The novelty of using technology to learn a language wears thin very quickly, so you need to be able to show students that the way you use it really does have significant advantages for enhanced learning collaborative writing 


\subsection{Listening Skills}

Record digital audio versions of some of the reading texts from the book, using a site such as https://audioboom.com/. This will enable you to help students revise the texts that they have read in previous lessons and see how much they can recall.

\subsection{Creating 'cloze' activities}

Use a cloze test creator, such as http://l.georges.online.fr/tools/cloze.html to create interactive web-based activities based on the texts from your course book. Select the focus of the words you remove from the text or just remove random ones. This can be a great way to revise texts that students have worked with in previous lessons. Try to train students to create their own tests to test themselves when revising or reviewing their work.

\subsection{Speaking assignments}

Get students to send you spoken reports or assignments based on course book materials. I recommend using http://mailvu.com/index.htm as it will enable you to give feed back to the students too.

\subsection{Visual sentences}

Ask your students to write example sentences using new vocabulary to show what the word means and how it is used, then ask them to copy these into WWW.pimpampum.net/phrasr/. This will give them a pictorial version of their sentences which they can copy as a record.

\subsection{Multimedia texts}

You can use https://storify.com/ to find and collect resources for online receptive skills practice. Use the search engine to find relevant texts, videos, images or audio files and then drag them onto publishing stage. This way you can create activities which encourage students to use multiple sources to find information.

\subsection{SMS texts}

You can convert short texts to SMS texting or online chat language using http://transl8it.com/. This is really useful to add an extra level of engagement with shorter texts from your coursebook

\subsection{Phonemic texts}

You can use http://www.photransedit.com/online/text2phonetics.aspx in a similar way to the SMS text transcriber. Just type or paste in your text and the website will transcribe it into phonemic script for you. This is a great timesaver for transcribing vocabulary records or creating sentences to exemplify the words and then transcribing them.

\subsection{Controlled practice drills}

We can use http://WWW.Voxopop.com/ by recording the model sentence and allowing the students to access these models online, listen and then record their own versions of the drill. They can do this by simply recording directly to the site from their computer.

\subsection{Using a digital exercise book}

Instead of getting students to write notes and homework assignments on paper, you can get them to use a digital journal as an exercise book and do their written assignments in it. The site https:/penzu.com/ allows your students to set up a free exercise book which stores all their entries and allows them to email individual entries to their teachers for comment.

\subsection{Text to Word cloud}

You can use http://WWW.wordle.net/ to create a word cloud for each text your students use in class. Take out these word clouds and put them around the walls of the classroom, then get the students to wander around the classroom and see how much of the information from each text they can remember. You can also put 
word clouds onto your projector and get the students to discuss them in pairs to see what they remember about the text.

\subsection{Sync.in - http://sync.in/}

This site enables you to make writing tasks collaborative by creating a piece of digital paper where up to four students can work together. You can share the URL of the page with the groups or pairs of students you want to work together so they can then type into the same digital text on any computer. The contribution of each person who changes the text will be colour-coded so you can see who has done the work.

\subsection{Flickriver - http://www.flickriver.com/}

This site gives you access to a continuous stream of images based on any key word search. It's ideal to display on a projector and you can show the images full-screen. You can also use it to get students brainstorming vocabulary on a topic or to use as a picture dictionary.

\subsection{PHRAS.IN - http://phras.in/}

This site enables you to compare similar words and see how they are used differently. It does this by searching the internet for examples of each word in use. It's great for researching collocations and seeing how they can be used in context.

\subsection{Forvo - http://www.forvo.com/}

This site is a collective pronunciation dictionary of world languages. It is user-created so anyone can submit or ask for the pronunciation of a word. The pronunciation examples are linked to location and tagged by gender so you can find multiple examples of the same word and compare the different accents. You can also download audio files of the words. This is a great resource for teaching pronunciation, especially if you are looking for a particular accent.

\subsection{Howjsay - http://howjsay.com/}

This is a pronunciation dictionary which has audio examples of each word. It shows the results within the related word family, making it easy to compare the pronunciations of words in their different forms.

\subsection{Phrasr - http://www.pimpampum.net/phrasr/}

This site enables you to build sequences of images based on sentences.

\subsection{Memorize Now - http://www.memorizenow.com/}

This site was built to help people memorize texts. You simply paste in the text or dialogue you want to remember and then click to start removing words from the text.

\subsection{Tools for learners - http://www.scoop.it/t/tools-for-learners}

This is an online magazine which profiles a collection of different web-based tools similar to the ones above. It would also be useful to have some form of video-editing software.

It's also worth remembering that most of the modern phones that many of our students carry around with them are capable of recording video,and, in the case of some smartphones the video can even be edited on the phone using free apps.

\section{Why are video sites useful in learning English?}

- Clips on sites are generally quite short, and therefore, they are appropriate for the demands that authentic materials can place on the concentration span of our learners.

- Most clips are appropriately edited or chunked so that they appear complete; this means that students don't have the sense of frustrated expectations that comes when you only show a portion of a film in class. 
- Video is an incredibly powerful medium for contextualizing language and helping students to deduce meaning and appropriacy from context.

- Video can also convey vital information about culture and specifically the culture of communication, such as body language and other paralinguistic features, that are absent from the kinds of audio materials we often use in class.

- Many younger students are visually stimulated by video and can find it more engaging than other forms of material.

- Involving students in the creation of video materials can help them to develop some really useful $21^{\text {st }}$ century literacy skills.

- Video can rapidly convey an enormous amount of information, even when students don't understand the language they are hearing, so can still be useful for other kinds of activity apart from listening.

- Most video-sharing websites supply an embed code, which means you can effectively copy the code and use the content within your own online-learning materials without breaking copyright.

- Students can access online video-sharing websites from home: this makes it possible to use these kinds of materials to make homework assignments much more motivating.

\section{Tips for Exploiting Online Video}

- This should go without saying, but expects you must watch the complete clip yourself first and ensure that it, and any surrounding advertising, comments or further links that may be displayed, are culturally and age-appropriate before sharing with students. If there are advertisements around it or a part of the clip that you would rather not let your students see, then there are ways to delete or hide. But always be aware that even in clips that other teachers have used or recommended, things can change in quite a short period of time.

- Make sure that you use clips with a purpose; don't just play them to entertain and expect your students to learn something.

- Video is a visual medium, so be sure to think about how you can exploit the visual aspect to support learning.

- Be aware of the target language level and grade your tasks appropriately.

- Check that the sites you use have some form of reporting, highlighting or the ability to flag up inappropriate content or comments and then teach your students how to use these.

- If you decide to start creating and sharing videos on your own channel, be sure to check out the various different services that are available. If you plan to be doing this a lot with your students, it might even be worth seeing if your school will pay for a subscription site where you can have more control over the person who sees the content.

\section{Teaching Suggestions and Activities}

\section{1. 'Flip' Your Classroom}

This is a concept that has become very popular in mainstream education recently. It centres around the idea that we can get students to watch the 'input' or lecture part of a class at home and then do the more practical part at school. We can extend this to English language teaching and give students video clips to watch at home - this could be language presentations or grammar explanations - and then get them to do more practical speaking or writing activities in the classroom where the teacher can support them. If you don't have the time or ability to create your own presentation videos, you can probably find some ready-made ones on YouTube which might be appropriate. 


\subsection{Story Retelling}

Find short video clips for your students to watch and get them to write about what they saw. This works particularly well with silent or animated films which rely strongly on visual elements. Students can do the writing on paper or post their completed compositions to a class blog or website along with the clip they watched.

\subsection{Film or Music Video Reviews}

Use online music videos or film trailers and get your students to review them for homework. There are lots of sites where you can find film or video reviews that you can use as a model in class before they do their own review for homework.

\subsection{Script it}

You can set video clips as a kind of dictation activity and get students to watch the clips at home and write out the script (be sure that it isn't a clip they can find the script to on Google); then in class they can compare their scripts and correct them.

\subsection{Re-enact it}

Find a clip with around four to five people in. Assign one of the roles from the clip to each person in the class and tell them to watch the clip and prepare to come into class and act it out. When the students come to class, create groups with each of the characters in and ask the students to rehearse their clip together. Once they have had some time to practise, you could get them to act it out in class and vote on the best performance.

\subsection{Understanding Character and Relationships}

Try to find a clip with a number of people in (clips that include a party, dinner party or other social scenes are usually quite effective). Ask the students to watch the clip at home and make notes about the relationships between the people in the clip. You could give them a list of questions to guide them, such as How well do they know each other?, Which ones are related?, Which people like each other?, Which have more formal relationships? etc. You could also ask them to analyze the characters on a more personal level, e.g. Which of the characters do you like?, Which do you feel you have the most in common with? etc. In class, they can discuss their analysis and justify it using the visual clues they saw in the clip.

\subsection{Comparing Cultures}

Try to find some quite ordinary scenes from the target culture. Get your students to watch these at home and to think about how they differ from their own culture. Things to focus on could be clothes, degrees of formality, greetings, proxemics (how close to each other people sit or stand when interacting), kinds of food or drink, etc. In class, students could discuss these and consider the consequences that ignoring these kinds of social norms may have for a person's ability to integrate into the culture.

Tools for video-sharing

\section{8. www.eslvideo.com}

This site has a huge collection of user-generated online quizzes based around web-based videos. The quizzes have been created by language teachers and are graded according to level. The quality of the quiz questions seems to vary quite a lot, so be sure to try the quizzes out before sharing them with your students and check that there are no incorrect answers or typos. If you register (for free), you can also use the site to create your own quizzes as well as creating your own teacher code which enables your students to send you their quiz results.

You can download a onestopenglish video screencast tutorial on using ESLvideo and a printable how-to guide at the links at the top right-hand side of this page.

In this how-to video, Nik Peachey shows you how to create video quizzes using the web-based tool ESLvideo. 


\section{9. http://safeshare.tv}

This is a really useful site which enables you to create a frame around a YouTube video so that the students can watch the video without any other distractions from things like comments or advertising that may appear around it. You can also use the site to edit the clip so that only a small section of it is played. It's free and very quick and easy to use.

\subsection{0. http://dotsub.com}

This site tends to host a lot of educational video content in multiple languages. The reason it is included in this section is because, as the name suggests, it also enables you to take videos from other websites and add subtitles to them. You have to register to do this and the site includes a short tutorial to show you how. This would be a really useful activity to get students to do. They could either use the site to transcribe or they could add translation subtitles.

\subsection{1. www.lyricstraining.com}

This site has a huge collection of music videos in multiple languages. Visitors to the site are able to do interactive listening activities based on listening to the song and typing the lyrics. They can choose the level of difficulty and this controls how many words are removed from the lyrics. At advanced level, all the words are removed. Students can also register and track their score. You can also use the site to add your own favorite videos and create activities for them, so if there is a song your students really like, you can use the site to turn it into a really motivating listening activity.

Again, there are always two sides of the coin. Using technology is not that easy as it seems. There may be technical errors, issues with the server, power-cut and so many other problems, but probing into the needs of the time,we must keep using the technology for better understanding and greater output.

\section{References}

[1] http://c4lpt.co.uk/top100tools/

[2] http://www.gc-solutions.net/blog/category/tools-technologies/

[3] https://www.learnupon.com/25-elearning-tools-need/ 